\section{Desafios da atenção à violência doméstica contra crianças e adolescentes no Programa Saúde da Família em cidade de médio porte do Estado do Rio de Janeiro, Brasil}

\author{
Challenges for dealing with cases of domestic \\ violence against children and adolescents through \\ the Family Health Program in a medium-sized \\ city in Rio de Janeiro State, Brazil
}

\author{
${ }^{1}$ Faculdade de Odontologia, \\ Centro Universitário Serra \\ dos Órgãos, Teresópolis, \\ Brasil. \\ 2 Instituto de Medicina \\ Social, Universidade do \\ Estado do Rio de Janeiro, \\ Rio de Janeiro, Brasil. \\ 3 Mestrado em Saúde da \\ Família, Universidade \\ Estácio de Sá, Rio de Janeiro, \\ Brasil. \\ 4 Instituto da Saúde da \\ Comunidade, Universidade \\ do Estado do Rio de Janeiro, \\ Rio de Janeiro, Brasil. \\ Correspondência \\ C. L. Moraes \\ Instituto de Medicina Social, \\ Universidade do Estado do \\ Rio de Janeiro. \\ Rua São Francisco Xavier \\ 524, 7o andar, blocos $D e E$ \\ Rio de Janeiro, $R J$ \\ 20559-900, Brasil. \\ clmoraes@ims.uerj.br
}

\begin{abstract}
This qualitative case study aimed to analyze the challenges faced by the Family Health Program (FHP) teams in dealing with domestic violence against children and adolescents in Teresópolis, Rio de Janeiro State, Brazil. The sample consisted of 25 professionals from three family health teams. Data were collected through face-to-face semi-structured thematic interviews and submitted to content analysis. Findings included the health professionals' detection of cases of domestic violence among families enrolled in the program, often associated with drug use and drug dealing, alcoholism, family breakdown, and poverty. Collaboration with the community and difficulty in inter-sector actions were identified as challenges for detecting, reporting, and monitoring cases. Most professionals felt insecure in dealing with such cases, due to lack of appropriate knowledge and skills. The study concludes that it is essential to managers, staff and community discuss the problem and means to approach it in the context of the territories.
\end{abstract}

Domestic Violence; Child; Adolescent; Family Health Program; Notice
Geórgia Rosa Lobato 1

Claudia Leite Moraes 2,3

Marilene Cabral do Nascimento 4

\section{Introdução}

A violência contra crianças e adolescentes é reconhecida como um problema de saúde pública que afeta toda a sociedade, sem distinção de sexo, raça ou condição social. O problema é ainda mais grave na infância, visto que crianças são vítimas preferenciais da violência ocorrida no âmbito doméstico. No espaço extradomiciliar, esta predomina contra adolescentes e adultos jovens ${ }^{1}$.

Segundo a Organização Mundial da Saúde (OMS), estima-se que no ano 2000 tenha havido cerca de 60 mil homicídios de menores de 15 anos em todo o mundo. Entretanto, em face das dificuldades quanto à identificação das situações de violência, avalia-se que o número de óbitos decorrentes do problema seja muito superior 2 .

As estimativas de incidência e prevalência dos casos de abuso que não foram a óbito também chamam a atenção. Em termos globais, estudos recentes apontam uma grande variação quanto à sua magnitude nos diferentes contextos socioculturais. A prevalência de violência física grave contra a criança nos 12 meses anteriores às entrevistas no final da década de 90, por exemplo, foi estimada em 4,9\% nos Estados Unidos, $8 \%$ na Itália, 22,6\% no Egito e 51,3\% na Coreia do Sul 2.

No Brasil, a magnitude do problema também preocupa. Em inquérito populacional realizado em dez capitais das cinco regiões brasileiras, no ano de 1999, contemplando 1.600 pessoas com idade superior a 15 anos, $14 \%$ dos entrevistados 
afirmavam ter apanhado quase todos os dias quando eram crianças ${ }^{3}$. Em 2002, estudo realizado em São Gonçalo, Rio de Janeiro, envolvendo 1.685 adolescentes de escolas públicas e particulares, constatou que $14,6 \%$ referiram ter sofrido violência física grave desferida pelo pai ou pela mãe ao longo da vida; $11,8 \%$ dos entrevistados testemunharam ou vivenciaram violência sexual na família e $48 \%$ deles sofreram violência psicológica de pessoas significativas 4 . Estudos em serviços de saúde confirmam a relevância do problema 1,3 .

Dentre outras iniciativas governamentais, o Estatuto da Criança e do Adolescente (ECA) de 1990 4, a Política Nacional de Redução da Morbimortalidade por Acidentes e Violência de 20017 e a Política Nacional de Promoção da Saúde de 20065 tornaram-se marcos no enfrentamento do problema pelo Estado brasileiro. Porém, apesar dos inegáveis avanços, ainda restam muitos passos a serem dados na promoção de bons tratos às crianças e aos adolescentes.

Apesar de o aprofundamento dos determinantes da violência doméstica contra crianças e adolescentes fugir ao escopo do artigo, há que se ressaltar que, por envolver questões macroestruturais, tais como as ligadas à estrutura de poder, aspectos socioeconômicos, questões de relacionamento interpessoal, questões de cunho individual, seu enfrentamento depende de uma larga articulação entre setores sociais, que envolva não só o setor da saúde, mas também de segurança, educação, judiciário, entre outros.

No que concerne ao setor da saúde, a literatura revela que este ainda tem dificuldades na abordagem do problema, uma vez que atua, na maior parte das vezes, apenas no tratamento de lesões e traumas que resultam das agressões 6. Como assinalam Moura \& Reichenheim 1, seja por falta de conhecimentos, seja por temerem implicações legais e constrangimentos relacionais em seus territórios de trabalho, muitos profissionais abandonam os casos, responsabilizando-se apenas pelas medidas emergenciais. Contudo, este tipo de abordagem tem se mostrado insuficiente e espera-se que os profissionais de saúde possam atuar também na prevenção de novos casos, mediante ações multiprofissionais e intersetoriais.

O Programa Saúde da Família (PSF), por meio da atuação de equipes multiprofissionais, busca acompanhar de perto as famílias em seu contexto territorial, de forma a responder às demandas apresentadas pela clientela, mas também a desenvolver ações de vigilância em saúde 7 (Ministério da Saúde. http://dab.saude.gov.br/atencao basica.php, acessado em 03/Jul/2012). No caso da violência doméstica, isto significa a identificação de aspectos relacionais, culturais, sociais, econômicos e ambientais que possam estar contribuindo para suscitar e perpetuar situações de maus-tratos, como também o desenvolvimento de respostas capazes de prevenir novos casos.

A proximidade entre as equipes multiprofissionais e as comunidades, nos territórios adscritos ao PSF, possibilita àquelas conhecer a história e a dinâmica das famílias, perceber suas interrelações, formas de comunicação e de resolução de conflitos, ampliando, assim, as possibilidades de detecção e prevenção da violência doméstica. No entanto, apesar das supostas possibilidades para lidar com o problema, é comum a queixa das equipes no que concerne ao parco conhecimento sobre o tema, à falta de estrutura para lidar com os casos, ao desconhecimento do fluxo e das motivações da notificação de casos e às dificuldades de uma abordagem integrada $\mathrm{e}$ intersetorial. Dessa forma, estudos que tragam ao debate as diferentes formas de lidar com a violência doméstica no âmbito do PSF podem oferecer subsídios que orientem a qualificação e ampliação das ações do setor da saúde diante da violência, bem como integração mais efetiva deste setor em redes intersetoriais sensíveis ao problema.

Visando a contribuir para um maior aprofundamento da discussão sobre como abordar o problema no âmbito da saúde da família, este estudo tem como objetivo analisar a percepção dos profissionais das equipes de saúde da família sobre a violência em seu território de atuação e sobre os desafios para a notificação dos casos, como também para a atenção às famílias em situações de violência.

\section{Materiais e métodos}

Trata-se de um estudo de caso com utilização de metodologia qualitativa. $\mathrm{O}$ caso em estudo é o da abordagem da violência doméstica por profissionais de saúde da família no Município de Teresópolis, cidade serrana do Estado do Rio de Janeiro, situada a $87 \mathrm{~km}$ da capital.

Com uma população estimada em 162.070 habitantes, concentrada na área urbana (83\%), segundo o IBGE (Instituto Brasileiro de Geografia e Estatística) para o ano de 2009, Teresópolis vem se desenvolvendo economicamente suportada principalmente por seu setor primário, sendo atualmente o mais importante produtor de hortifrutigranjeiros em todo o estado. Em 2000, o IDH (Índice de Desenvolvimento Humano) do município ficou em 0,790, abaixo do índice da Região Sudeste $(0,84)$ e do estado $(0,832)$.

Dados do relatório de gestão da Prefeitura Municipal de Teresópolis (2009) indicam que 
88, $1 \%$ de adolescentes e jovens residentes (15-24 anos) completaram apenas as quatro primeiras séries do Ensino Fundamental. Do total populacional que ocupa postos de trabalho, apenas 29,6\% estão em trabalhos formais, índice bem abaixo do encontrado para o Estado do Rio de Janeiro $(40,6 \%)$. Somente $30,7 \%$ dos trabalhadores formais de Teresópolis contam com rendimento acima de três salários mínimos. Ademais, existem 24 aglomerados subnormais (favelas) mapeados. Tais características nos fazem crer que a cidade seja um solo fértil à violência, na medida em que esta é socialmente construída e está relacionada a iniquidades sociais e escassez de oportunidades e perspectivas, principalmente em regiões metropolitanas 6,8,9.

Quando analisados os óbitos conforme grupos de causas, verifica-se que, no período de 2006-2009, as mortes por causas externas ocuparam o quarto lugar dentre os principais motivos. Infelizmente, não há registros sistematizados dos casos que não foram a óbito, mas, considerandose as características sociais do município e outros estudos sobre o tema realizados no Estado do Rio de Janeiro 3,10,11, supõe-se que os dados de mortalidade são apenas a ponta do iceberg.

Quanto ao PSF, dados da Secretaria Municipal de Saúde informam que, no ano de 2009, 16 equipes respondiam pela cobertura de aproximadamente $29 \%$ dos habitantes de Teresópolis (Sistema de Informação da Atenção Básica. http://www.datasus.gov.br/siab/siab.htm, acessado em 20/Nov/2007), totalizando 55.249 pessoas, distribuídas em 16.739 famílias. Assim, considerando-se os atributos que se buscou conhecer nesta pesquisa, foram estudadas três equipes de saúde da família, selecionadas de acordo com os seguintes critérios de inclusão: (a) ter pelo menos dois anos de implantação; (b) estar localizada em área de maior vulnerabilidade social; (c) estar situada em área urbana com alto índice de violência. Definiu-se o tempo mínimo de dois anos de implantação por pressupor-se que as equipes já teriam aprofundado o contato com as condições sociais e de saúde das famílias assistidas, além de, especificamente, terem identificado formas de lidar com a violência doméstica contra crianças e adolescentes em seus territórios de atuação.

Foram convidados a participar da pesquisa todos os profissionais que compunham as equipes selecionadas: três médicos, três enfermeiros, dois auxiliares de enfermagem, três técnicos de enfermagem e 14 agentes comunitários de saúde, o que perfez um total de 25 profissionais. A coleta de dados foi realizada em novembro de 2008, por intermédio de 25 entrevistas individuais, com roteiro temático composto por perguntas abertas, previamente testado com nove pro- fissionais de outras equipes de saúde da família do município.

Os dados foram gravados e transcritos. A fim de garantir o anonimato, as falas foram codificadas segundo as categorias profissionais e o número de participantes: M1, M2 etc. para médicos, E1, E2 etc. para enfermeiros, AE para auxiliares de enfermagem e ACS pra agentes comunitários de saúde.

O tratamento e interpretação dos dados basearam-se na Análise de Conteúdo com abordagem temática 12,13. Uma sistematização inicial das informações colhidas permitiu a percepção dos principais núcleos de sentido emergentes na pesquisa de campo. A identificação destes núcleos levou em conta as regularidades do discurso e os sentidos frequentes e ímpares presentes nas falas. Posteriormente, os dados foram organizados e classificados em categorias temáticas, que consideraram os objetivos da pesquisa em associação aos núcleos de sentido que emergiram no campo. Foram definidas quatro categorias temáticas, que dão título às sessões de resultados e discussão apresentadas a seguir.

A discussão dos resultados considerou conceitos norteadores no PSF, tais como trabalho em equipe 14 , integralidade 15,16 e intersetorialidade. Buscaram-se as relações de trabalho no interior da equipe de saúde da família, as dinâmicas de comunicação e a forma como seus membros se articulam considerando suas especificidades. O conceito de integralidade permitiu um olhar sobre o grau de articulação das medidas de promoção da saúde, prevenção das violências, atenção individual e coletiva no âmbito da violência doméstica contra a criança e o adolescente. $\mathrm{O}$ conceito de intersetorialidade foi útil para analisar as práticas de articulação das equipes com outras instituições/setores da sociedade, como, por exemplo, o Conselho Tutelar e a Vara da Infância, Juventude e Idoso.

O projeto de pesquisa foi registrado no Sistema Nacional de Informações sobre Ética em Pesquisa Envolvendo Seres Humanos (SISNEP) sob o $n^{\circ}$. 0065.0.308.000-08, tendo sido aprovado pelo Conselho de Ética em Pesquisa da Universidade Estácio de Sá. Todos os profissionais entrevistados assinaram um termo de consentimento livre e esclarecido, conforme normas que regulamentam as pesquisas envolvendo seres humanos preconizadas na Resolução $n^{\circ}$. 196/96, do Conselho Nacional de Saúde. 


\section{Resultados e discussão}

Violências nos territórios assistidos pelas equipes de saúde da família

Os profissionais entrevistados destacaram vários tipos de violência em seus territórios de atuação, que envolvem parceiros íntimos, adolescentes, crianças e idosos. Associaram estas formas de violência à desestruturação da família, ao uso e tráfico de drogas, ao desemprego e à pobreza.

“[...] Eu vejo até uma violência muito maior por parte dos adolescentes em relação ao idoso, aos seus familiares, do que dos familiares com os adolescentes e crianças. Isso talvez seja uma coisa, né? Uma controvérsia grande... mas a violência neles, e não com eles. Isso eu vejo bastante. E a violência geral muito grande. Muito alcoolismo, muita violência contra a mulher, isso aí tem bastante também" (M1).

“[...] Desentendimento mesmo por causa do pouco dinheiro na casa... Mas não é assim uma coisa que dê grandes consequências. A consequência é a privação do conforto do alimento, às vezes uma energia elétrica que não foi paga, tá sendo cortada, né? Eu acho que isso é uma violência pra família, que fica sem energia, fica às vezes sem essa possibilidade de conforto" (ACS11).

Esses dados corroboram a literatura que sinaliza a multicausalidade e complexidade da violência, relacionando-a a problemas sociais, emocionais, psicológicos e cognitivos, os quais se manifestam geralmente em associação ao uso de substâncias psicoativas, abuso de álcool e outras drogas, ou ainda à iniciação prematura da atividade sexual 2,9.

Dos 25 entrevistados, 11 ressaltaram que os adolescentes não são apenas vítimas, mas também perpetradores de violência contra familiares e membros da comunidade. Essa situação foi relacionada à dificuldade de diálogo na família e ao crescimento do uso e tráfico de drogas.

“Em relação à criança, muitas crianças ociosas, tem a parte da escola, às vezes até frequenta aquele tempo, mas fora aquilo é muita ociosidade, muito furto. Crianças furtando, crianças consumindo drogas, crianças já praticando sexo bem recente mesmo, de maneira, até assim querendo espantar mesmo" (M1).

"[...] não é nem dos pais, hoje em dia, a violência, às vezes a violência parte até do adolescente mesmo com os pais, mas não assim de bater, agredir não. É violência verbal. Não tem mais respeito. Mais os adolescentes do que os pais com eles" (ACS1).

A citação abaixo denota a ênfase que os entrevistados deram ao convívio familiar na formação ética e social de crianças e adolescentes, bem como em seu desenvolvimento emocional. Deixa clara, ainda, a importância do testemunho da violência entre os pais como forma de transmissão intergeracional da violência.

“[...] os adolescentes principalmente, vão observando a convivência do pai e da mãe, vê que é só briga dentro de casa, já sai aquela criança já revoltada, chega na rua vai e qualquer coisinha vai e bate também porque sabe que não acontece nada em casa... que a violência já começa dentro de casa então eles não querem nem saber. [...] Tem uma mulher ali na minha área que ela trata os filhos com pedaço de pau... só fala gritando" (ACS1).

Os participantes expressaram a ideia de um ciclo perverso, no qual os mais jovens tendem a reproduzir ao longo da vida a violência vivenciada desde a infância no interior de suas famílias e comunidades. Segundo eles, as consequências desta violência atingem a qualidade de vida, prejudicando em particular os estudos e a saúde de crianças e adolescentes.

“Afeta no sentido... até na própria formação dessa criança, desse adolescente e... no medo que se cria neles e até de espelho, né?! Eles acabam, alguns, veem aquilo com tanta naturalidade que pegam aquilo e fazem a mesma coisa depois na vida deles. Afeta no estudo, na saúde, de uma forma geral. [...] Na saúde porque existe... tem muita violência doméstica aqui, aí a mãe sai de casa, o pai, ai é criado pelo avô, aí não se alimenta direito, vive pela rua, é largado mesmo, é criado pelos outros, aí influencia bastante na saúde deles, né?! De qualidade de vida" (E2).

A associação entre família e violência também é destacada na literatura, como ilustra documento da Secretaria Municipal de Saúde de São Paulo 19 , segundo o qual o avanço da violência expressa a distorção ou destruição de importantes valores sociais, como o da família enquanto espaço social de amor, carinho e proteção.

\section{Percepção e detecção da violência doméstica} contra crianças e adolescentes

A violência doméstica foi considerada pelos profissionais como algo difícil de detectar. Segundo os entrevistados, essa dificuldade se deve a uma característica inerente a esse tipo de violência, que é o abafamento dos casos. São atitudes escondidas pelos familiares, as quais raramente chegam espontaneamente até a equipe de saúde.

"Porque as coisas são mais abafadas mesmo. [...] Pode existir, mas são mais abafadas. Porque... é mais fácil você descobrir que tem uma gestante, né? Que tem um hipertenso, um diabético. Mas uma violência? Pode ser abafado" (ACS1). 
As entrevistas apontaram que a detecção da violência doméstica se dá principalmente por meio da comunicação com outras instituições, principalmente as escolas, mas também mediante denúncia de vizinhos aos agentes comunitários e visitas domiciliares realizadas pela equipe. Em algumas entrevistas, foi possível perceber a valorização do trabalho dos ACS na detecção dos casos; já em outras, percebem-se os ACS em lugar exatamente oposto, com mais dificuldade de apontar as situações de violência do que os demais membros da equipe.

“As pistas... é... as maiores pistas, pra gente, vêm através do colégio, da creche e dos agentes comunitários. [...] São os casos que os agentes comunitários trazem pra gente, aí é que a gente vai pesquisar. Porque às vezes eles mesmos ficam sabendo pelos vizinhos ou por alguém assim, porque a família mesmo não conta" (E3).

"O agente comunitário, por fazer parte da comunidade, pelo menos na minha área, não costuma trazer esses casos pra mim. Quando relata algum caso ele relata algum caso que já foi denunciado e que... assim, por algum vizinho. Nunca vem aqui pra unidade, entendeu? Por exemplo, ou o colégio, ou um vizinho denunciou e já tá tudo resolvido, eles me relatam. Eu nunca pego um caso, pego suspeita" (M3).

$\mathrm{O}$ abuso contra a criança e o adolescente foi identificado pelos entrevistados principalmente como práticas de negligência, violência física e abandono. Como aponta a literatura, a violência física é o tipo de abuso mais reconhecido, pois deixa marcas visíveis $5,18,19,20$.

"Aí teve uma casa que eu visitei, que a mãe tava com um prato, almoçando, e a menina do lado pedindo comida. A mãe [disse] 'daqui a pouco eu te dou'. Aí eu fiquei lá pra ver se ela ia dar mesmo. Porque eu fiquei sabendo que não dava, né? Aí eu tive que ficar visitando, por isso ela passou a cuidar melhor do filho" (ACS6).

Tendo em vista a situação de miséria e pobreza às quais muitas famílias estão expostas, a identificação de atitudes negligentes pode também ser uma tarefa difícil. Como exemplificado na fala abaixo, muitas vezes, o profissional não consegue discernir se a negligência é da família ou do Estado, que não provê condições mínimas de vida aos cidadãos. Essa dúvida interfere na ação a ser desencadeada.

"[...] tava numa visita e cheguei numa casa que tinha uma menina de treze anos tomando conta de umas seis crianças. De dois, de três, de tudo quanto era idade, sozinhos. E eu perguntei 'Vocês ficam sempre sozinhos?' 'Nós ficamos, sim. Muito animal no quintal, beira de estrada... aí eu liguei pro Conselho Tutelar, aí o Conselho Tutelar falou: 'Nós vamos até averiguar'. Mas olha a situ- ação: o que que é preferível, a irmã tá cuidando das crianças em casa ou a mãe tá cuidando? Porque, se a mãe sai pra trabalhar e as crianças tão ali sendo cuidadas pelos irmãos mais velhos, pelo menos a mãe tá sustentando aquele lar. Agora, se a mãe fica em casa porque o Conselho Tutelar obrigou porque as crianças não podem ficar sozinhas, quem vai manter essa família? [...] até o Conselho Tutelar fica em situação difícil em alguns casos, né?" (ACS7).

Com base nesses relatos, é possível afirmar que os casos de violência doméstica contra crianças e adolescentes são presentes nos territórios pesquisados e associados principalmente a negligência, violência física e pobreza extrema. Entretanto, sua detecção é ainda limitada, sendo viabilizada principalmente pelas escolas e os ACS.

\section{Notificação dos casos}

A notificação de casos de violência doméstica contra crianças e adolescentes é apresentada na legislação como um direito das vítimas e um dever dos profissionais de saúde 19,21. Estes devem reconhecer o momento adequado para notificar, preparar a família esclarecendo-a sobre a obrigatoriedade da unidade de saúde em proceder à notificação, o seu teor e significado, a quem é dirigida, suas vantagens e possíveis desdobramentos 22 .

Todavia, as entrevistas revelaram dúvidas e principalmente receio dos profissionais quanto à notificação dos casos de violência contra crianças e adolescentes, em especial daqueles não confirmados. Alguns profissionais, inclusive, declararam desconhecer a presença da ficha de notificação compulsória para violência na unidade de saúde em que trabalham.

"Olha, essa ficha eu acredito que tenha aqui, que a gente já viu. [...] Mas eu não... eu não vi não. [...] Porque nós aqui temos ficha pra quase tudo" (ACS8).

Não obstante, o medo de exposição se revelou o principal problema a inibir a notificação de violência nas equipes estudadas. A ficha de notificação inclui a identificação do profissional que preenche o documento, expondo-o ao risco de sofrer retaliações por parte dos agressores.

"Agora, esse tipo de coisa é meio perigoso, meio complicado. Isso pode parar na Justiça, entendeu?" (ACS9).

"[...] a gente não pode fazer nada porque isso dai a gente tem que ter prova, né? Se a vizinha quiser denunciar ao Conselho Tutelar aí é com ela... o posto não pode denunciar. Ela queria, ela procurou o agente de saúde pro agente de saúde denunciar, pro posto denunciar e o posto não 
denuncia, né? Quer dizer, agora tem essas notificações que a gente tem que fazer, mas nós não somos obrigados a fazer. Ninguém quis fazer pra não se expor" (E1).

Este temor é citado em outros estudos 18,19,22,23, sendo apontado como um desafio para a garantia do sistema de vigilância das violências. Como se pode perceber nas falas abaixo, os ACS são a categoria profissional mais exposta às ameaças de violência por parte das famílias, entre outros motivos, porque moram na comunidade onde trabalham.

"Eaté os vizinhos, dependendo da área que for, que tem a área aqui que é um pouco pesada, eles ficam com medo de falar. [...] É uma área mais... tem tráfico, muito carente, tem muita coisa errada lá, então eles [ACS] têm medo de... que eles são trabalhadores da área e são moradores, né? [...] Aî eles têm medo" (E1).

"É, bate. Não vê aonde bate... Outro dia eu falei com ela: 'Poxa, você tem que ver onde bate nesse menino, vai que bate em algum lugar aí e machuque mesmo ele?' 'Que se dane, leva pro hospital!' Eu falei: 'Não é assim, não...você não tem medo de eu denunciar?' E ela: 'te bato também, hein!' (ACS3).

Dessa forma, a territorialização e adscrição da clientela, assim como a constituição de vínculo com os moradores, ao mesmo tempo em que facilitam a detecção da violência doméstica, dificultam a notificação dos casos. Por isso, os entrevistados propuseram o anonimato na notificação, de forma a não identificar o profissional responsável e a unidade de saúde onde o documento é emitido.

"O medo todo é esse, sair o nome aqui do posto. Às vezes a gente até comenta com alguém... gente do Fórum. Até comenta, mas pede sigilo pra não falar do posto. Ou pra não falar da gente. Eu sou uma mesmo que faço isso de vez em quando. Mas eu tenho medo e a maioria aqui também acredito que tenha medo" (ACS3).

A necessidade de autoproteção dos membros das equipes de saúde combinada ao reconhecimento ético e profissional da importância de se fazer algo diante da violência doméstica propiciou a adoção de práticas alternativas à notificação dos casos. Por exemplo, uma agente comunitária declarou que não notifica as situações de abuso contra crianças e adolescentes que acontecem em sua comunidade, mas leva os casos verbalmente a uma conhecida sua, que trabalha na Vara da Infância. "É assim... porque eu tenho uma conhecida da Vara da Infância, aí a gente comenta, ah, como é que tá lá? Assim, assim... é informal" (ACS3).

Outra atitude adotada pelos profissionais é o encaminhamento de casos de violência ao hospital, para que a notificação seja feita por lá.
“A gente encaminhou para o Hospital das Clínicas. Aí, lá no Hospital das Clínicas tem aquele negócio de fazer a ocorrência e aí que foi encaminhado pro Conselho Tutelar. [...] Nós encaminhamos para o hospital porque aqui a gente não tinha nem como fazer" (AE1).

A maioria dos entrevistados declarou que os médicos e enfermeiros são os profissionais da equipe responsáveis pelo preenchimento da ficha de notificação. As falas dos médicos e enfermeiros indicaram que a notificação pode ser feita por qualquer integrante da equipe de Saúde da Família, porém confirmaram que eles tendem a assumir a responsabilidade por essa tarefa.

"Os enfermeiros ou os médicos. São eles que fazem essa parte. [...] Porque, na verdade, a nossa função aqui, de auxiliar e técnico, é atender a demanda sim, mas a gente não tem muito contato assim, diretamente. É esporadicamente que a gente fica sabendo de um caso desse, mas quem sabe tudo mesmo são eles" (AE 1).

Os dados da pesquisa confirmam os achados de Gonçalves \& Ferreira 22 (p. 371), segundo os quais a decisão de notificar "não se prende à orientação geral da legislação [...] e é influenciada por fatores de ordem pessoal dos profissionais, pelas especificidades do caso atendido e pelas próprias estruturas dos serviços".

\section{Atenção às famílias em situações de violência}

Percebe-se certa dualidade entre os profissionais quanto às responsabilidades do PSF em face de situações de violência doméstica. Alguns consideraram que a violência não deve constar na agenda das equipes de saúde da família. Para estes, o Conselho Tutelar, o serviço municipal de assistência social e as escolas são as instâncias competentes para lidar com o problema.

"Então o que envolve a saúde do nosso usuário, do nosso público em geral a gente tá sempre tentando atender. Agora, quando se trata de violência doméstica, a gente tem um cuidado muito grande em ter certeza, realmente ver e procurar o órgão competente pra isso. Aí a gente liga pro Conselho Tutelar, ou tenta entrar em contato com a assistente social da prefeitura, do município, que é a pessoa mais competente pra avaliar. O posto procura se manter neutro nessa situação" (E1).

"Quando ela é declarada, [...] aí a gente tem que tomar uma providência, encaminhar ao Conselho Tutelar e coisa que o valha. A escola normalmente é que faz esse papel. E a gente se sente confortável. [...] Se esse fosse nosso papel a gente já teria se organizado pra tanto" (ACS9).

Outros profissionais entenderam que o PSF também tem responsabilidades no acompanhamento de famílias em situações de violência do- 
méstica e na prevenção de novos casos: "Porque é um trabalho nosso, a gente tá vendo” (ACS3).

A quase totalidade dos entrevistados declarou, entretanto, não se sentir habilitada a lidar com casos relacionados à violência contra crianças e adolescentes. Alguns sugeriram a necessidade de apoio de psicólogos para orientar os profissionais das equipes de Saúde da Família e as famílias envolvidas, mas afirmaram que não participaram até o momento de qualquer atividade de educação permanente sobre o tema da violência doméstica.

"Eu acho muito complicado, sabe? Não sei se a gente também tem tanto preparo assim. [...] Eu não sei te dizer como é que a gente vai lidar com isso. Podia ter um profissional, um psicólogo, para dar um suporte, né?" (M3).

Apesar de se sentirem sem suficiente preparo, os profissionais consideraram que as visitas domiciliares são o contexto adequado para o acompanhamento das famílias em situação de violência doméstica, pois permitem, de forma regular, o contato com as pessoas envolvidas e a orientação destas. Os ACS prioritariamente, seguidos dos enfermeiros, foram identificados como os mais aptos para o acompanhamento dessas famílias no âmbito das equipes de saúde da família.

“A gente acompanha através do agente comunitário, só. E do colégio. [...] O agente comunitário vai fazendo as visitas e vai vendo se continua tendo ou se está tendo algum tipo de violência pra poder nos passar, né?" (AE1).

No entanto, pudemos perceber que alguns ACS não encaminhavam à equipe os casos que detectavam porque desconheciam que deveriam fazê-lo, porque a equipe enfrentava problemas na integração entre seus membros, ou ainda porque avaliavam que a equipe nada poderia fazer para resolver a situação. Os ACS informaram que seus contatos na equipe de saúde se concentravam principalmente entre eles e com o enfermeiro; o acesso ao médico se limitava ao espaço das reuniões.

“Aí eu não falei, não comentei com ninguém não, porque esse assunto não é muito abordado. Não é, entendeu? Então, não tem como passar pro enfermeiro. [...] porque eles não podem fazer nada, entendeu? Não tem como eles fazerem nada. Então, eu.. eu, por exemplo, não tenho informações de que eu pudesse falar com alguém, entendeu? O quê que o enfermeiro pode fazer? Nada" (ACS3).

Alguns profissionais relataram a organização de atividades educativas em grupos, dirigidas aos pais e principalmente aos adolescentes, como uma estratégia para promover a saúde, os bons tratos e contribuir na construção da paz nas famílias e comunidades. Informaram que contam eventualmente com a parceria de outras instituições na realização dessas atividades, como o Conselho Tutelar, as escolas e a Vara da Infância, da Juventude e do Idoso.

“... gosto muito de fazer a parte de trabalho de educação em saúde. Eu acho que devia ser por aí [...] com grupos pra poder captar e aí poder ouvir e poder chegar a saber o que tá acontecendo na casa de cada um e fazer um projeto pra eles. [...] Transformá-los para o bem, né? [...] E a gente dessa maneira, fazendo esses grupos, podendo falar sobre essas partes também: drogas, tudo, sexo, sexualidade. Só deles falarem também já ajuda, né?" (M1).

A parceria de outras instituições foi bastante valorizada pelos entrevistados, mas considerada insuficiente, principalmente nas ações dirigidas aos adolescentes. De acordo com os profissionais, falta informação ao adolescente, mas principalmente oferta de atividades esportivas, artísticas e de cursos profissionalizantes, como forma de tirá-los da ociosidade e prepará-los para um futuro melhor.

“Mas não é só a gente. Tá faltando um pouco de esporte, não tem muito incentivo de coisas que eu acho que a pessoa tem que... tem que ter nessa idade. [...] É um trabalho mais de educação, mais de grupo de adolescente, oficina de adolescente pra ensinar a eles a fazer um trabalho musical, um trabalho de esporte, um trabalho artístico [...] Secretaria de Esporte, secretaria de... sei lá, Turismo. Oficinas pra preparar, fazer cursos profissionalizantes pra eles. Pensar um pouquinho no futuro, né? Uma coisa pra tirar eles dessa ociosidade que leva a fazer essas coisas" (M1).

Como se pode perceber, os entrevistados não se sentem habilitados a lidar com situações de violência doméstica; além disso, não há um consenso entre eles sobre suas responsabilidades diante desses casos. Visitas domiciliares e grupos educativos são suas principais estratégias; as ações intersetoriais, embora presentes, mostram-se ainda frágeis e eventuais.

\section{Considerações finais}

O estudo apontou que as políticas públicas que preconizam a contribuição do setor de saúde na detecção e enfrentamento de violências - particularmente a violência doméstica contra crianças e adolescentes - não garantem a percepção, por parte dos profissionais de saúde da família de Teresópolis, de que o problema deva ser enfrentado também no âmbito do PSF. Paralelamente, os resultados encontrados confirmaram o que a literatura sugere a respeito das dificuldades dos profissionais em acompanhar famílias em situ- 
ações de violência: a maioria se sente insegura e pouco qualificada no manejo de casos de violência doméstica 1,8,9,11.

O temor de sofrer represálias por parte dos agressores diante da notificação dos casos, quando não paralisa as ações, dificulta o acompanhamento aos envolvidos de acordo com o que a legislação preconiza. Esse quadro expressa a necessidade de um diálogo franco entre gestores e profissionais, a fim de que sejam revistos aspectos da legislação e da organização dos serviços em desacordo com as condições concretas de atuação e segurança dos profissionais de saúde da família. O desconhecimento sobre o fluxo de encaminhamento e os desdobramentos das notificações, tanto para o profissional quanto para os envolvidos em situações de violência, é uma questão importante a ser considerada, levandose em conta que a subnotificação encobre a real dimensão do problema e inibe potenciais estratégias governamentais e não governamentais para sua prevenção e enfrentamento 23 .

Diante dessas fragilidades, parece razoável afirmar que, no que se refere à violência doméstica contra crianças e adolescentes, a implementação de práticas integrais e intersetoriais eficazes e efetivas, que incluam ações e serviços de promoção, prevenção e reabilitação, individuais e coletivos, voltados para as vítimas e também para os agressores, ainda não é realidade no PSF de Teresópolis. As ações relatadas se mostraram eventuais e frágeis, pautadas em um cuidado descontínuo, fragmentado e frequentemente focado em aspectos biológicos.

Consideramos que, diante da complexidade exigida para abordar e acompanhar famílias em situação de violência, são necessárias ações de educação permanente dos profissionais de saúde, abordando-se conhecimentos e práticas bem-sucedidas para a identificação de casos, no acolhimento e acompanhamento da clientela em questão. No entanto, a educação permanente dos profissionais não é suficiente, e um ponto importante a se considerar é a fragilidade dos gestores da Estratégia Saúde da Família em relação à organização do processo de trabalho das equipes. Tal vulnerabilidade se traduz na falta de definições claras a respeito das atribuições das equipes diante da violência doméstica, entre outros aspectos. Particularidades do território, como a estrutura de poder nas comunidades e suas formas de organização, por exemplo, também merecem fazer parte da discussão. Logo, tornase necessário unir gestores, equipe e comunidade na discussão do problema e dos meios como abordá-lo no contexto dos territórios.

\section{Resumo}

O artigo analisa os desafios encontrados na abordagem da violência doméstica contra crianças e adolescentes por profissionais do Programa Saúde da Família (PSF). Trata-se de estudo de caso qualitativo realizado em Teresópolis, Rio de Janeiro, Brasil. A amostra compreendeu 25 profissionais de três equipes de PSF. Os dados foram colhidos por meio de entrevistas individuais, com utilização de roteiro temático semiestruturado e analisados por meio da Análise de Conteúdo. Dentre os resultados, destaca-se a percepção dos profissionais de que há casos de violência doméstica nas famílias adscritas, frequentemente associada ao uso e tráfico de drogas, alcoolismo, desestruturação da família e pobreza. O vínculo com a comunidade e a dificuldade para ações intersetoriais foram identificados como desafios para detecção, notificação e acompanhamento dos casos. Em sua maioria, os profissionais sentem-se inseguros pela falta de conhecimentos e habilidades para o manejo dos casos. Conclui-se que é fundamental unir gestores, equipe e comunidade na discussão do problema e dos meios de abordá-lo no contento dos territórios.

Violência Doméstica; Criança; Adolescente; Programa de Saúde da Família; Notificação 


\section{Colaboradores}

G. R. Lobato, C. L. Moraes e M. C. Nascimento contribuíram no planejamento do estudo; orientação na coleta e análise de dados; elaboração da versão final do artigo.

\section{Referências}

1. Moura ATMS, Reichenheim ME. Estamos realmente detectando violência familiar contra a criança em serviços de saúde? A experiência de um serviço público no Rio de Janeiro, Brasil. Cad Saúde Pública 2005; 21:1124-33.

2. Krug EG, Dahlberg LL, Mercy JA, Zwi AB, Lozano R. World report on violence and health. Geneva: World Health Organization; 2002.

3. Assis SG, Avanci JQ, Santos NC, Malaquias JV, Oliveira RVC. Violence and social representation in teenagers in Brazil. Rev Panam Salud Pública 2004; 16:43-51.

4. Brasil. Lei no ${ }^{\circ} 8.069$ de 13 de julho de 1990. Dispõe sobre o Estatuto da Criança e do Adolescente. Diário Oficial da República Federativa do Brasil 1990; 16 jul.

5. Brasil. Portaria MS/GM n ${ }^{\circ} .737$ de 16 de maio de 2001. Política Nacional de Redução de Morbimortalidade por Acidentes e Violências. Diário Oficial da União 2001; 18 mai.

6. Deslandes SF. $\mathrm{O}$ atendimento às vítimas de violência na emergência: prevenção numa hora dessas? Ciênc Saúde Coletiva 1999; 4:81-94.

7. Andrade COM, Barreto ICHC, Bezerra RC. Atenção primária à saúde e estratégia saúde da família. In: Campos GWS, Minayo MCS, Akerman M, Drumond Júnior M, Carvalho YM, organizadores. Tratado de saúde coletiva. 2a Ed. São Paulo: Editora Hucitec/Rio de Janeiro: Editora Fiocruz; 2009. p. 783-836.

8. Minayo MCS. Violência, um problema social que afeta a saúde pública. Divulg Saúde Debate 2006; 35:23-35.

9. Minayo MCS. Violência e saúde. Rio de Janeiro: Editora Fiocruz; 2006.
10. Rocha PCXM, Moraes CL. Violência familiar contra a criança e perspectivas de intervenção do Programa Saúde da Família: a experiência do PMF/ Niterói (RJ, Brasil). Ciênc Saúde Coletiva 2010; 16: 3285-96.

11. Moura ATMS, Moraes CL, Reichenheim ME. Detecção de maus-tratos contra a criança: oportunidades perdidas em serviços de emergência na cidade do Rio de Janeiro, Brasil. Cad Saúde Pública 2008; 24:2926-36.

12. Bardin L. Análise de conteúdo. Lisboa: Edições 70; 2007.

13. Minayo MCS. O desafio do conhecimento: pesquisa qualitativa em Saúde. São Paulo: Hucitec/Rio de Janeiro: ABRASCO; 1992.

14. Peduzzi M. Equipe multiprofissional de saúde: conceito e tipologia. Rev Saúde Pública 2001; 35:103-9.

15. Cecílio LCO. As necessidades de saúde como conceito estruturante na luta pela integralidade e equidade na atenção em saúde. In: Pinheiro R, Mattos RA, organizadores. Os sentidos da integralidade na atenção e no cuidado à saúde. Rio de Janeiro: Instituto de Medicina Social, Universidade do Estado do Rio de Janeiro/ABRASCO; 2001. p. 113-26.

16. Louzada AFB, Barros MEB. Integralidade e trabalho em equipe no campo da saúde: entre normas antecedentes e recentradas. In: Pinheiro R, Barros MEB, Mattos RA, organizadores. Trabalho em equipe sob o eixo da integralidade: valores, saberes e práticas. Rio de Janeiro: Instituto de Medicina Social, Universidade do Estado do Rio de Janeiro/ ABRASCO; 2007. p. 37-52. 
17. Coordenação de Desenvolvimento de Programas de Políticas de Saúde. Caderno de violência doméstica e sexual contra crianças e adolescentes. São Paulo: Secretaria Municipal de Saúde de São Paulo; 2007.

18. Secretaria de Assistência à Saúde, Ministério da Saúde. Notificação de maus-tratos contra crianças e adolescentes pelos profissionais de saúde: um passo a mais na cidadania em saúde. Brasília: Secretaria de Assistência à Saúde, Ministério da Saúde; 2002.

19. Secretaria de Políticas de Saúde, Ministério da Saúde. Violência intrafamiliar: orientações para prática em serviço. Cadernos de Atenção Básica n 8. Brasília: Ministério da Saúde; 2002. (Série A. Normas e Manuais Técnicos, 131).

20. Reichenheim ME, Hasselman MH, Moraes CL. Consequências da violência familiar na saúde da criança e do adolescente: contribuições para a elaboração de propostas de ação. Ciênc Saúde Coletiva $1999 ; 4: 109-21$.
21. Pires ALD, Miyazaki MCOS. Maus-tratos contra crianças e adolescentes: revisão da literatura para profissionais de saúde. Arq Ciênc Saúde 2005; 12:42-9.

22. Gonçalves H, Ferreira A. A Notificação da violência intrafamiliar contra crianças e adolescentes por profissionais de saúde. Cad Saúde Pública 2002; 18:315-9.

23. Luna GLM, Ferreira RC, Vieira LJES. Notificação de maus-tratos em crianças e adolescentes por profissionais da Equipe Saúde da Família. Ciênc Saúde Coletiva 2010; 15:481-91.

Recebido em 18/Mar/2011

Versão final reapresentada em 21/Abr/2012

Aprovado em 25/Jun/2012 